\title{
Completion proctectomy following transanal endoscopic microsurgery for early rectal cancer
}

\author{
Katarina Levic-Souzani ${ }^{1}$, Orhan Bulut ${ }^{1,2}$ \\ 'Gastrounit-Surgical Division, Center for Surgical Research, Copenhagen University Hospital, Hvidovre 2650, Denmark. \\ ${ }^{2}$ Institute of Clinical Medicine, University of Copenhagen, Copenhagen 1165, Denmark.
}

Correspondence to: Dr. Orhan Bulut, Gastrounit-Surgical Division, Center for Surgical Research, Copenhagen University Hospital, Hvidovre 2650, Denmark. E-mail: Orhan.Bulut@regionh.dk

How to cite this article: Levic-Souzani K, Bulut O. Completion proctectomy following transanal endoscopic microsurgery for early rectal cancer. Mini-invasive Surg 2018;2:25. http://dx.doi.org/10.20517/2574-1225.2018.35

Received: 31 May 2018 First Decision: 23 Jul 2018 Revised: 2 Aug 2018 Accepted: 2 Aug 2018 Published: 16 Aug 2018

Science Editor: Gordon N. Buchanan Copy Editor: Jun-Yao Li Production Editor: Huan-Liang Wu

\begin{abstract}
Transanal endoscopic microsurgery (TEM) has proven to be a safe and effective procedure in removal of rectal lesions and may be used in treatment of early rectal cancer in selected patients. In cases when the TEM specimen shows non-radical resection, or histological high-risk factors, completion proctectomy (CP) is warranted. It is debated when it is the best time to perform CP following TEM. It is furthermore uncertain whether CP leads to an increased risk of abdominoperineal excision. Herein, we review the available literature regarding controversial issues with early completion proctectomy following TEM.
\end{abstract}

Keywords: Transanal endoscopic microsurgery, total mesorectal excision, completion proctectomy, early rectal cancer

\section{INTRODUCTION}

Transanal endoscopic microsurgery (TEM) was first introduced in 1984 by Buess et al. ${ }^{[1]}$ as a minimally invasive surgical technique for the resection of large rectal adenomas. With TEM technique, a full-thickness en bloc excision is possible in the entire rectum, which may be technically difficult by other local procedures such as transanal excision (TAE). TEM has proven to be a safe and effective procedure in removal of rectal lesions ${ }^{[2-9]}$. TEM has furthermore considerably lower morbidity and mortality compared with conventional radical rectal resection for rectal tumors ${ }^{[10-15]}$. For patients with tumors in the lower part of the rectum, local excision by TEM may offer a chance for preserved bowel continuity and avoidance of rectal amputation with subsequent consequences. 
The best management for early rectal cancer is still controversial. In terms of oncological results, local excision of early rectal cancer ( $\mathrm{pT} 1$ ) by TEM has equivalent outcomes to radical resection ${ }^{[10,11,13,14]}$. Due to abovementioned advantageous attributes, the use of TEM for early rectal cancer is now considered a viable option in selected patients, and may be offered to patents with lesions pre-operatively staged as T1No, with tumor diameter $<4 \mathrm{~cm}$ involving less than $30 \%$ of the rectal wall circumference, and no histological risk factors ${ }^{[16-20]}$. Preoperative staging with endoscopic rectal ultrasound (ERUS) and magnetic resonance imaging (MRI) of rectal lesions aid in decision making of selection for local treatment or radical resection. However, understaging is not uncommon ${ }^{[9,21-25]}$. Furthermore, unexpected malignancy is reported in $18 \%$ $43 \%$ of preoperatively assumed benign lesions in the rectum ${ }^{[9,26-28]}$.

Early completion proctectomy $(\mathrm{CP})$ is recommended in cases when the TEM specimen shows non-radical resection, low tumor differentiation or lymphovascular invasion, because of the increased risk of recurrence and lymph node metastasis in such cases. Some concerns have been raised regarding early CP. There may be increased morbidity due to two procedures being performed in the same area within a short period of time. The healing and scar formation and mesorectal fibrosis from the previous TEM procedure may disrupt the normal tissue planes and compromise the operative field. This may increase the difficulty during dissection in $\mathrm{CP}$, and result in higher perforation rates, poor resection quality, prolonged operative time and higher conversion rates. The fibrotic scarring following TEM procedure may also contribute to tissue retraction and binding of the previous tumor site to the pelvic floor, which may lead to an increased abdominoperineal excision (APE) rate. We aim to review the available literature regarding controversial issues with early completion proctectomy following TEM.

\section{OVERALL MORBIDITY AND APE RATE}

Overall morbidity following rectal cancer surgery is about $40 \%$, regardless of approach (open or laparoscopic $)^{[29]}$. A concern with $\mathrm{CP}$ is that a previous operation in the rectum by TEM may influence surgical dissection plans, resulting in an increased risk for local complications. Regarding morbidity rates following $\mathrm{CP}$, the results vary among studies, and interpretation is limited by small study samples and methodological issues. In a study reported by Piessen et al. ${ }^{[30]}, 14$ consecutive patients who underwent full thickness TAE and subsequent radical resection, were matched and compared with 25 patients with primary radical resection. There was no significant difference in overall morbidity $(64.3 \% v s .32 \%, P=0.112)$. However, a higher rate of surgical complications was shown in the TAE group $(57.1 \% v s .20 \%, P=0.048)$. The frequency of specific surgical site complications, including anastomotic leakage and pelvic abscess, was also higher in the TAE group ( $42.8 \%$ vs. $8 \%, P=0.032$ ). The study cohort consisted of patients with preoperative chemoor radiation therapy (5/14 patients in the TAE group), and the defect in the rectal wall was left unsutured in all patients, which may have contributed to the higher local compliactions. Although not fully investigated yet, the non-sutured defect at the TEM site may weaken the rectal wall and result in higher risk of perforation during $\mathrm{CP}$.

In contrast, Morino et al. ${ }^{[31]}$ didn't find any difference in the incidence of complications. They compared 17 patients with laparoscopic total mesorectal excision (LTME) after TEM with 34 patients undergoing primary TME and found that the results on rate of intraoperative complications and conversion to open surgery did not differ significantly ( $5.9 \%$ vs. $8.8 \%, P=0.854$, and $5.9 \% v s .5 .9 \%, P=0.528$, respectively). There was, however, a significantly longer operating time in the TEM group (206 $\mathrm{min} v s .188 \mathrm{~min}, P=0.025$ ). Although there were only 25 patients in each group, the study by Levic et al.$^{[32]}$ is the largest comparative study on early CP up to date. Twenty-five patients with early CP were matched and compared with 25 patients with primary TME. There was no difference in intra- or postoperative complications, operating time or estimated blood loss between the two groups. Only a minority of the patients in both groups were oper- 
ated with laparoscopy, hence it is therefore not possible to say whether previous TEM had an influence on conversion rates.

The fibrotic changes in the mesorectum and granulation tissue surrounding the previous TEM site is also a concern following CP, because of potentially higher APE rates. Although recognized among surgeons, there is still a lack of evidence on the subject in the literature. Hompes et al ${ }^{[33]}$ reported a $14 \%$ APE rate in a study consisting of 36 patients with CP. Piessen et al. ${ }^{[30]}$ didn't find any difference in rate of sphincter saving procedures performed. One of the matching factors was, however, the procedure type. Likewise, there was no difference in the APE rate in the study by Levic et al ${ }^{[32]}$, although the control group was also matched based on procedure type. Morino et al ${ }^{[31]}$ performed matching based on gender, age, American Society of Anesthesiologist (ASA) score, body mass index (BMI), tumor size, and tumor distance from the anal verge. A significantly higher APE rate was observed in the CP group $(41.2 \%$ vs. $11.7 \%, P=0.028)$. Following multivariate analysis, previous TEM was the only independent predictor for APE (OR 4.13, 95\%CI 1.09-15.55, $P$ $=0.046)^{[31]}$. In a study by van Gijn et al. ${ }^{[34]}$ where 59 patients with CP were compared with 881 patients from the TME-trial (with preoperative radiotherapy) the results showed a higher rate of colostomies in patients with previous TEM (OR 2.51, 95\% CI 1.30-4.86, $P=0.006$ ). The TEM group had, however, a higher rate of Hartmann procedures, but the same rate of APE.

\section{PATHOLOGICAL FINDINGS}

Another concern with CP after TEM may be pathologic findings and completeness of the mesorectal fascia (MRF). The risk of poorer quality of the mesorectum may be due to the scar formation and mesorectal fibrosis from the previous TEM, as previously mentioned. In Morino's study, where a higher rate of APE was reported, no difference was seen in the integrity of the mesorectum, with preserved integrity in all patients included in the study ${ }^{[31]}$. Likewise, although there were incomplete pathological data on all patients, Levic et al ${ }^{[32]}$ didn't find any difference in the number of patients with nearly complete or complete MRF (11 vs. 16 patients, $P=0.31$ ). The perforation rate at or near the previous TEM site was, however, $20 \%$ in the CP group. Piessen et al ${ }^{[30]}$ reported major difference in completeness of the mesorectum. The MRF was complete in only $4 / 25$ with previous full-thickness TAE $v s .24 / 25$ in the group with primary TME $(P<0.001)$. Furthermore, tearing of the rectal wall down to the mucosa occurred was more frequent in the group with CP (35.7\% vs. $0 \%, P=0.009)$. Again, it is worth to mention that the defect after the full thickness excision was left unsutured in all patients, which may have had an influence on these figures. None of the studies comparing $\mathrm{CP}$ with primary TME showed difference in the circumferential margin involvement rate (Levic et al. ${ }^{[32]}: 4 \%$ in both groups; Morino et al. ${ }^{[31]}: 0 \%$ in both groups; Piessen et al ${ }^{[30]}: 14 \%$ vs. $4 \%$ ).

\section{ONCOLOGICAL RESULTS}

The reported high perforation rates during CP lead to worries regarding survival in these patients, as iatrogenic rectal perforation is one of the most important risk factors for both local and distant recurrence and impaired survival ${ }^{[35-37]}$. Results regarding long-term oncological results in patients with $\mathrm{CP}$ are, however, very limited. Borschitz et al. ${ }^{[38]}$ s study on 21 patients with CP following TEM showed low rates of both local recurrence and distant metastases (6\%). The 5-year disease-free survival (DFS) was $75 \%$ in patients with T1R0, and 93\% in patients with T1/R1 or those with "high risk factors". Similarly, Hompes et al. ${ }^{[33]}$ reported good survival rates with 1-year DFS of $91 \%$ and 5-year DFS of $83 \%$. Local recurrence occurred in $3 \%(1 / 36)$ and distant metastases in $14 \%$ (5/36). However, only one study comparing CP with primary TME has reported oncological results ${ }^{[32]}$. There was no difference in rate of local recurrence between CP and primary TME ( $0 \% v$ s. $8 \%, P=0.49$ ), or rate of distant metastases ( $4 \% v$ s. $12 \%, P=0.26)$. Cumulative survival rates were not reported. The median follow-up time was 25 and 19 months, respectively. The remaining two studies comparing CP with primary TME only reported short-term results, and oncological data is therefore unfortunately lacking from these studies ${ }^{[30,31]}$. 


\section{WHEN TO PERFORM EARLY COMPLETION SURGERY}

Whether the time between TEM and CP as an influence on outcomes is not known. The precise definition of "early" and the time frame in which CP should be performed is unclear. Most studies report outcomes after CP perform surgery within 6-8 weeks of TEM. Levic et al ${ }^{[32]}$ defined "early" as CP within 12 weeks of TEM. The median time to $\mathrm{CP}$ was 37 days with a range between 14 and 90 days. Similarly, Issa et al. ${ }^{[39]}$ had a median time of 47 days to CP (range 32-70) and Piessen et al. ${ }^{[30]} 37$ days (range 7-120). van Gijn et al. ${ }^{[34]}$ reported longer interval of 15 weeks to the completion of TME, due to logistic reasons, but the decision of CP was made immediately after the TEM results. In Morino's study only patients with laparoscopic TME within 8 weeks of TEM were included, with a median of 40 days ${ }^{[31]}$. Hahnloser et al ${ }^{[40]}$ had even shorter criteria, and performed CP following TAE within 30 days, with median time of 7 days. So far only a few studies have reported outcomes based on the time frame to CP. Hompes et al. ${ }^{[33]}$ found that poor quality specimen was more frequent after an interval from TEM to CP of more than 7 weeks. The median time to CP was 2 months with range between 0.5 to 8.7 months. However, Morino et al ${ }^{[31]}$ didn't find any difference in outcomes among patients operated within 30 days of TEM or more than 30 days after TEM.

\section{FUTURE ASPECTS}

Minimal invasive surgery has gained an increasing interest, especially in the field of rectal surgery. The transanal approach of rectal dissection is gaining wider use and acceptance, and the first randomized trial comparing taTME with laparoscopic TME is currently ongoing ${ }^{[41]}$. The advantages of trans-anal TME (taTME) include better visualization and possibility of approaching the lesion from below. This may have benefits for patients in need for CP following TEM. Approaching the lesion from below may limit the traction on the scarred tissue and thereby possibly reducing the risk of perforation and other surgical site complications. So far, only one study has reported outcomes of patients with CP by taTME. Letarte et al. ${ }^{[42]}$ reported results on 41 patients with CP following TEM, of which 11 were operated by taTME and 30 with conventional TME. The patients with taTME had significantly less intraoperative blood loss $(205 \mathrm{~mL} v s$. $365 \mathrm{~mL}, P=0.04)$. More interestingly, there was lower rate of conversion to open surgery $(9.1 \% v \mathcal{~ s . 5 7 \% , P <}$ $0.001)$ and higher sphincter preserving rates $(100 \% v s .50 \%, P=0.01)$ despite of the significantly lower distance of tumor from the anal verge in the taTME group.

\section{CONCLUSION}

Completion proctectomy following TEM appears safe. Nevertheless, there seems to be an increased risk for intraoperative rectal perforation, which the operating surgeon needs to be aware of. The possible higher incidence of APE following TEM needs to be investigated in larger studies. The drawback in the current literature is the small series reporting outcome of CP following TEM. The published studies on the subject have different methodological approaches, and limited number of patients, which increases the risk of type II error. In order to further investigate whether there is a higher risk of APE and morbidity (particularly rectal perforation, which may influence survival) it is necessary to conduct more studies with higher number of patients, especially those comparing $\mathrm{CP}$ with primary TME.

\section{DECLARATIONS}

\section{Authors' contributions}

Substantial contribution to conception and design, and acquisition of data, and analysis and interpretation of data: Levic-Souzani K, Bulut O

Drafting the article and revising it critically for important intellectual content: Levic-Souzani K, Bulut O Giving the final approval of the version to be submitted and any revised version: Levic-Souzani K, Bulut O

\section{Availability of data and materials}

Not applicable. 


\section{Financial support and sponsorship}

None.

\section{Conflicts of interest}

All authors declare that there are no conflicts of interest.

\section{Ethical approval and consent to participate}

Not applicable.

\section{Consent for publication}

Not applicable.

\section{Copyright}

(c) The Author(s) 2018.

\section{REFERENCES}

1. Buess G, Hutterer F, Theiss J, Böbel M, Isselhard W, Pichlmaier H. A system for a transanal endoscopic rectum operation. Chirurg 1984;55:677-80. (in German)

2. Arezzo A, Arolfo S, Allaix ME, Bullano A, Miegge A, Marola S, Morino M. Transanal endoscopic microsurgery for giant circumferential rectal adenomas. Color Dis 2016;18:897-902.

3. Serra-Aracil X, Gràcia R, Mora-López L, Serra-Pla S, Pallisera-Lloveras A, Labró M, Navarro-Soto S. How to deal with rectal lesions more than $15 \mathrm{~cm}$ from the anal verge through transanal endoscopic microsurgery. Am J Surg 2018; doi: 10.1016/j.amjsurg.2018.04.014.

4. Darwood RJ, Wheeler JMD, Borley NR. Transanal endoscopic microsurgery is a safe and reliable technique even for complex rectal lesions. Br J Surg 2008;95:915-8.

5. Laliberte AS, Lebrun A, Drolet S, Bouchard P, Bouchard A. Transanal endoscopic microsurgery as an outpatient procedure is feasible and safe. Surg Endosc 2015;29:3454-9.

6. Bach SP, Hill J, Monson JR, Simson JN, Lane L, Merrie A, Warren B, Mortensen NJ; Association of Coloproctology of Great Britain and Ireland Transanal Endoscopic Microsurgery (TEM) Collaboration. A predictive model for local recurrence after transanal endoscopic microsurgery for rectal cancer. Br J Surg 2009;96:280-90.

7. Endreseth BH, Wibe A, Svinsås M, Mårvik R, Myrvold HE. Postoperative morbidity and recurrence after local excision of rectal adenomas and rectal cancer by transanal endoscopic microsurgery. Colorectal Dis 2005;7:133-7.

8. Maslekar S, Pillinger SH, Monson JR. Transanal endoscopic microsurgery for carcinoma of the rectum. Surg Endosc 2007;21:97-102.

9. Baatrup G, Elbrønd H, Hesselfeldt P, Wille-Jørgensen P, Møller P, Breum B, Qvist N. Rectal adenocarcinoma and transanal endoscopic microsurgery. Diagnostic challenges, indications and short term results in 142 consecutive patients. Int J Colorectal Dis 2007;22:134752.

10. Winde G, Nottberg H, Keller R, Schmid KW, Bünte H. Surgical cure for early rectal carcinomas (T1). Transanal endoscopic microsurgery vs. anterior resection. Dis Colon Rectum 1996;39:969-76.

11. De Graaf EJ, Doornebosch PG, Tollenaar RA, Meershoek-Klein Kranenbarg E, de Boer AC, Bekkering FC, van de Velde CJ. Transanal endoscopic microsurgery versus total mesorectal excision of T1 rectal adenocarcinomas with curative intention. Eur J Surg Oncol 2009;35:1280-5

12. Palma P, Horisberger K, Joos A, Rothenhoefer S, Willeke F, Post S. Local excision of early rectal cancer: is transanal endoscopic microsurgery an alternative to radical surgery? Rev Esp Enferm Dig 2009;101:172-8.

13. Lee W, Lee D, Choi S, Chun H. Transanal endoscopic microsurgery and radical surgery for T1 and T2 rectal cancer. Surg Endosc 2003; 17:1283-7.

14. Heintz A, Mörschel M, Junginger T. Comparison of results after transanal endoscopic microsurgery and radical resection for T1 carcinoma of the rectum. Surg Endosc 1998;12:1145-8.

15. Wu Y, Wu YY, Li S, Zhu BS, Zhao K, Yang XD, Xing CG. TEM and conventional rectal surgery for T1 rectal cancer: a meta-analysis. Hepatogastroenterology 2011;58:364-8.

16. Gorter RR, Eker HH, Gorter-Stam MA, Abis GS, Acharya A, Ankersmit M, Antoniou SA, Arolfo S, Babic B, Boni L, Bruntink M, van Dam DA, Defoort B, Deijen CL, DeLacy FB, Go PM, Harmsen AM, van den Helder RS, Iordache F, Ket JC, Muysoms FE, Ozmen MM, Papoulas M, Rhodes M, Straatman J, Tenhagen M, Turrado V, Vereczkei A, Vilallonga R, Deelder JD, Bonjer J. Diagnosis and management of acute appendicitis. EAES consensus development conference 2015. Surg Endosc 2016;30:4668-90.

17. van de Velde CJH, Boelens PG, Borras JM, Coebergh JW, Cervantes A, Blomqvist L, Beets-Tan RG, van den Broek CB, Brown G, Van Cutsem E, Espin E, Haustermans K, Glimelius B, Iversen LH, van Krieken JH, Marijnen CA, Henning G, Gore-Booth J, Meldolesi E, Mroczkowski P, Nagtegaal I, Naredi P, Ortiz H, Påhlman L, Quirke P, Rödel C, Roth A, Rutten H, Schmoll HJ, Smith JJ, Tanis PJ, Taylor C, Wibe A, Wiggers T, Gambacorta MA, Aristei C, Valentini V. EURECCA colorectal: multidisciplinary management: European consensus conference colon \& rectum. Eur J Cancer 2014;50:1.e1-34.

18. Glynne-Jones R, Wyrwicz L, Tiret E, Brown G, Rödel C, Cervantes A, Arnold D; ESMO Guidelines Committee. Rectal cancer: ESMO Clinical Practice Guidelines for diagnosis, treatment and follow-up. Ann Oncol 2017;28:iv22-40. 
19. Allaix ME, Arezzo A, Morino M. Transanal endoscopic microsurgery for rectal cancer: T1 and beyond? An evidence-based review. Surg Endosc 2016;30:4841-52.

20. Deborah Freedman-Cass N, Gregory KM, Cederquist L. NCCN Guidelines Version 3.2017 Panel Members Rectal Cancer Continue NCCN Guidelines Panel Disclosures. Available from: https://www.nccn.org/professionals/physician_gls/pdf/rectal.pdf. [Accessed May $16,2018]$

21. Marusch F, Ptok H, Sahm M, Schmidt U, Ridwelski K, Gastinger I, Lippert H. Endorectal ultrasound in rectal carcinoma--do the literature results really correspond to the realities of routine clinical care? Endoscopy 2011;43:425-31.

22. Ashraf S, Hompes R, Slater A, Lindsey I, Bach S, Mortensen NJ, Cunningham C; Association of Coloproctology of Great Britain and Ireland Transanal Endoscopic Microsurgery (TEM) Collaboration. A critical appraisal of endorectal ultrasound and transanal endoscopic microsurgery and decision-making in early rectal cancer. Color Dis 2012;14:821-6.

23. Bipat S, Glas AS, Slors FJ, Zwinderman AH, Bossuyt PM, Stoker J. Rectal cancer: local staging and assessment of lymph node involvement with endoluminal US, CT, and MR imaging--a meta-analysis. Radiology 2004;232:773-83.

24. Puli SR, Reddy JB, Bechtold ML, Choudhary A, Antillon MR, Brugge WR. Accuracy of endoscopic ultrasound to diagnose nodal invasion by rectal cancers: a meta-analysis and systematic review. Ann Surg Oncol 2009;16:1255-65.

25. Ptok H, Marusch F, Meyer F, Wendling P, Wenisch HJ, Sendt W, Manger T, Lippert H, Gastinger I. Feasibility and accuracy of TRUS in the pre-treatment staging for rectal carcinoma in general practice. Eur J Surg Oncol 2006;32:420-5.

26. Serra-Aracil X, Caro-Tarrago A, Mora-López L, Casalots A, Rebasa P, Navarro-Soto S. Transanal endoscopic surgery with total wall excision is required with rectal adenomas due to the high frequency of adenocarcinoma. Dis Colon Rectum 2014;57:823-9.

27. Serra-Aracil X, Mora-Lopez L, Alcantara-Moral M, Caro-Tarrago A, Gomez-Diaz CJ, Navarro-Soto S. Transanal endoscopic surgery in rectal cancer. World J Gastroenterol 2014;20:11538-45.

28. Absar MS, Haboubi NY. Colonic neoplastic polyps: biopsy is not efficient to exclude malignancy. The Trafford experience. Tech Coloproctol 2004;8:s257-60.

29. van der Pas MH, Haglind E, Cuesta MA, Fürst A, Lacy AM, Hop WC, Bonjer HJ; COlorectal cancer Laparoscopic or Open Resection II (COLOR II) Study Group. Laparoscopic versus open surgery for rectal cancer (COLOR II): short-term outcomes of a randomised, phase 3 trial. Lancet Oncol 2013;14:210-8.

30. Piessen G, Cabral C, Benoist S, Penna C, Nordlinger B. Previous transanal full-thickness excision increases the morbidity of radical resection for rectal cancer. Colorectal Dis 2012;14:445-52.

31. Morino M, Allaix ME, Arolfo S, Arezzo A. Previous transanal endoscopic microsurgery for rectal cancer represents a risk factor for an increased abdominoperineal resection rate. Surg Endosc 2013;27:3315-21.

32. Levic K, Bulut $\mathrm{O}$, Hesselfeldt $\mathrm{P}$, Bülow $\mathrm{S}$. The outcome of rectal cancer after early salvage TME following TEM compared with primary TME: a case-matched study. Tech Coloproctol 2013;17:397-403.

33. Hompes R, McDonald R, Buskens C, Lindsey I, Armitage N, Hill J, Scott A, Mortensen NJ, Cunningham C; Association of Coloproctology of Great Britain and Ireland Transanal Endoscopic Microsurgery Collaboration. Completion surgery following transanal endoscopic microsurgery: assessment of quality and short- and long-term outcome. Colorectal Dis 2013;15:e576-81.

34. van Gijn W, Brehm V, de Graaf E, Neijenhuis PA, Stassen LP, Leijtens JW, Van De Velde CJ, Doornebosch PG. Unexpected rectal cancer after TEM: outcome of completion surgery compared with primary TME. Eur J Surg Oncol 2013;39:1225-9.

35. Bülow S, Christensen IJ, Iversen LH, Harling H; Danish Colorectal Cancer Group. Intra-operative perforation is an important predictor of local recurrence and impaired survival after abdominoperineal resection for rectal cancer. Colorectal Dis 2011;13:1256-64.

36. Jörgren F, Johansson R, Damber L, Lindmark G. Risk factors of rectal cancer local recurrence: population-based survey and validation of the Swedish rectal cancer registry. Colorectal Dis 2010;12:977-86.

37. Eriksen MT, Wibe A, Syse A, Haffner J, Wiig JN; Norwegian Rectal Cancer Group; Norwegian Gastrointestinal Cancer Group. Inadvertent perforation during rectal cancer resection in Norway. Br J Surg 2004;91:210-6.

38. Borschitz T, Heintz A, Junginger T. The influence of histopathologic criteria on the long-term prognosis of locally excised pT1 rectal carcinomas: results of local excision (transanal endoscopic microsurgery) and immediate reoperation. Dis Colon Rectum 2006;49:1492506; discussion 1500-5.

39. Issa N, Fenig Y, Gingold-Belfer R, Khatib M, Khoury W, Wolfson L, Schmilovitz-Weiss H. Laparoscopic total mesorectal excision following transanal endoscopic microsurgery for rectal cancer. J Laparoendosc Adv Surg Tech 2018; doi: 10.1089/lap.2017.0399.

40. Hahnloser D, Wolff BG, Larson DW, Ping J, Nivatvongs S. Immediate radical resection after local excision of rectal cancer: an oncologic compromise? Dis Colon Rectum 2005;48:429-37.

41. Deijen CL, Velthuis S, Tsai A, Mavroveli S, de Lange-de Klerk ES, Sietses C, Tuynman JB, Lacy AM, Hanna GB, Bonjer HJ. COLOR III: a multicentre randomised clinical trial comparing transanal TME versus laparoscopic TME for mid and low rectal cancer. Surg Endosc 2016;30:3210-5.

42. Letarte F, Raval M, Karimuddin A, Phang PT, Brown CJ. Salvage TME following TEM: a possible indication for TaTME. Tech Coloproctol 2018;22:355-61. 